\title{
¿Cómo hablan los chilenos? Conocer la historia de un idioma para traducir.
}

\section{Entrevista al profesor Darío Rojas}

\author{
Meritxell Hernando Marsal \\ Universidade Federal de Santa Catarina (UFSC) \\ meritxellhmarsal@gmail.com \\ Mary Anne Warken Soares Sobottka \\ doutoranda - Universidade Federal de Santa Catarina (UFSC) \\ warkenespanholufsc@gmail.com
}

RESUMEN: Darío Rojas (Curicó, 1983) es doctor en Filología Hispánica por la Universidad de Valladolid y académico del Departamento de Lingüística de la Universidad de Chile. Sus investigaciones tratan sobre la formación de ideologías lingüísticas en Chile desde el siglo XIX en adelante, en el marco de la construcción del Estado-nación. En particular, con su trabajo se propone contribuir a identificar el rol de los discursos y los imaginarios sobre las lenguas (en especial el castellano y el mapudungun) en la construcción y legitimación de las desigualdades en el país, para lo cual ha adoptado el enfoque de la glotopolítica. Además de haber escrito numerosos artículos para revistas especializadas sobre estos temas, es autor del libro de divulgación ¿Por qué los chilenos hablamos como hablamos? Mitos e historia de nuestro lenguaje (2015). En esta entrevista, realizada en el marco de un proyecto de traducción de un poeta chileno al portugués, Rojas comenta las particularidades del castellano chileno y el carácter eminentemente político de las prácticas lingüísticas.

Palabras-clave: Darío Rojas, castellano de Chile, traducción literaria.

\section{How do Chileans speak? Know the history of a language to translate.}

\section{Interview with Profesor Darío Rojas}

ABSTRACT: Darío Rojas (Curicó, 1983) holds a PhD in Hispanic Philology from the University of Valladolid and is a Professor at the Department of Linguistics of the University of Chile. His research addresses the formation of linguistic ideologies in Chile from the 19th century onward, within the framework of the Nation-State construction. In particular, he seeks to identify the role of the 
discourse and of the imaginary about languages (especially Spanish and Mapudungun) in the construction and legitimization of social inequalities in Chile, adopting the approach of glotopolitics. Not only has he written numerous articles for specialized journals on these topics, but he is also the author of the popular book ¿Por qué los chilenos hablamos como hablamos? Mitos e historia de nuestro lenguaje (2015). In this interview, guided by the framework of a project to translate a Chilean poet into Portuguese, he comments on the particularities of Chilean Spanish and the eminently political character of linguistic practices.

Keywords: Darío Rojas, Chilian spanish, literary translation. 


\section{Introducción}

La entrevista con Darío Rojas (Curicó, 1983), lingüista y profesor de la Universidad de Chile, fue realizada en el marco de la investigación de doctorado sobre la traducción de poesía chilena al portugués brasileño, que Mary Anne Warken está llevando a cabo en el Programa de Pós-graduação em Estudos da Tradução de la Universidade Federal de Santa Catarina. Una de las preocupaciones de Mary Anne es la de no homogeneizar el castellano chileno que caracteriza los poemas y de acoger los elementos lingüísticos propios de esta lengua, como la presencia marcada del mapudungun. Es bien sabido que las variedades geográficas del castellano (así prefiere llamar a su lengua Darío Rojas, lo que ya muestra una posición política frente a la pretensión hegemónica peninsular) son muy diversas, tanto en la Península Ibérica como en América, y quien traduce al portugués brasileño debe poner atención a esta pluralidad para no reducirla a soluciones adaptadas al contexto de llegada que apagarían su especificidad. ¿Cómo visibilizar las variedades del castellano en traducción? Y especialmente ¿Cómo mostrar la chilenidad de un texto en traducción? ¿Y qué se juega en esa chilenidad?

Para poder pensar en estas cuestiones, Mary Anne Warken entró en contacto con el autor del libro ¿Por qué los chilenos hablamos como hablamos? Mitos e historia de nuestro lenguaje (2015), que amablemente contestó a la entrevista y habló del carácter político de la lengua, ya sea en su práctica cotidiana, como en la representación y las actitudes que se tienen hacia ella; de la riqueza del trabajo lexicográfico; de la artificialidad de las fronteras entre lenguas y dialectos, que tienen motivaciones ideológicas, y la apuesta por una concepción de la lengua como un conjunto heterogéneo de prácticas comunicativas influenciado por múltiples actores sociales; de las diversas codificaciones del mapudungun, de su carácter político, y de su importancia para mantener la vitalidad de esta lengua; de las principales características del castellano hablado en Chile y del papel del arte y la literatura para legitimarlo y darle visibilidad.

La entrevista, por tanto, nos muestra la riqueza del diálogo entre investigadores/as de diferentes áreas, en una comprensión de la traducción como proceso de conocimiento y actividad colaborativa que se nutre de intercambios y que es capaz de crear redes intelectuales. También, nos alerta de la necesidad de estrechar lazos entre las culturas de América Latina, para que en el proceso dialógico puedan realizarse proyectos de intercambio de conocimientos y manifestaciones culturales.

Meritxell H Marsal 


\section{¿Cómo hablan los chilenos? Conocer para traducir Entrevista al profesor Darío Rojas}

1. Mary Anne Warken (A): Primeramente, me gustaría que nos contases un poco sobre tu trabajo en la Universidad de Chile como docente y especialmente sobre tu proyecto respecto a las ideologías lingüísticas de los intelectuales chilenos hispanohablantes de fines del siglo XIX y comienzos del XX. Por favor, ¿podrías comentar los motivos de la elección de este período específico?

Darío Rojas (DR): En la Universidad de Chile enseño principalmente Historia de la Lengua Española y dirijo tesis sobre ideologías lingüísticas y glotopolítica. Lo que hay de común entre mi docencia y mi investigación es el interés por la historicidad del lenguaje, entendida no solo como su devenir en una cronología (el tradicional estudio del cambio lingüístico y la gramática histórica) sino como su relación dinámica con un contexto material. Me inspira la idea de que el lenguaje, en cuanto práctica social y política, es inherentemente político, así como lo son las representaciones y actitudes que tenemos hacia el lenguaje. Estas últimas, que es lo que en particular me interesa, forman parte de los procesos de constitución de dinámicas de poder y desigualdad. En cierto momento de mi carrera me interesé por las actitudes lingüísticas de los hispanohablantes chilenos, pero me di cuenta de que más allá de conocer estas actitudes, me interesaba saber ¿de dónde vienen estas actitudes, cómo se originaron y transformaron?, así como ¿a los intereses de quién responden, es decir, qué rol desempeñan en la lucha de clases? Así fue como terminé concentrándome en un recorrido crítico por el archivo desde los comienzos de la República de Chile, en la primera mitad del siglo XIX. Es en ese período donde se empiezan a movilizar los discursos e imaginarios sobre las lenguas que hoy podemos encontrar en Chile, tanto desde los estudios científicos del lenguaje como desde otros saberes y campos. El contexto de la formación y posterior consolidación del Estado-nación es clave para entender todo este problema y permite pensar el problema como algo político, que escapa por mucho a la disciplina de la lingüística.

2. (A): Has coordinado el Diccionario de uso del español de Chile (DUECh, 2010) y la revisión del léxico chileno del Diccionario de la lengua española de la Real Academia Española / Asociación de Academias de la Lengua Española (23 ed., 2014). También colaboraste en el Diccionario de americanismos de la misma institución (2009). Hoy coordinas el Diccionario fraseológico de uso del español de Chile. Todos estos trabajos son muy importantes para quienes 
estudian la traducción de literatura chilena, textos escritos en el castellano de Chile y, además, para pensar el doblaje y los subtítulos para las producciones cinematográficas producidas en Chile. ¿Cuál es la principal dificultad de realizar todos estos proyectos en los que has participado y cuáles las bellezas de coordinarlos?

(DR): Me dediqué profesionalmente a la lexicografía entre los años 2005 y 2017 aproximadamente, siempre en el marco de proyectos de la Academia Chilena de la Lengua o la Asociación de Academias de la Lengua Española (ASALE). Hoy estoy distanciado de la lexicografía académica. Las principales dificultades en ese tipo de trabajos son de carácter técnico: en el caso de la lexicografía académica chilena, todo es todavía muy artesanal, no se usan las infraestructuras informáticas adecuadas. Tampoco hay un proyecto realmente propio implementado, todavía todo funciona en las lógicas de ser una academia correspondiente (subsidiaria) de la Real Academia Española. En el caso de los diccionarios de la Asale, pasa que las academias americanas tienen relativamente poca injerencia en el proceso, funcionan casi como informantes o consultoras. Todo esto a veces hacía frustrante el trabajo, bien por falta de metodología adecuada o por falta de independencia. Por otro lado, haciendo lexicografía se aprende mucho de la lengua; de hecho creo que ahí fue donde más pude interiorizarme de cómo funciona la semántica, en comparación con mis estudios en la universidad. También pasa que para hacer lexicografía hay que aprender mucho de todo: arte, historia, ciencia, política, economía, artesanías, oficios, etc., porque hay que definir y entender conceptos que aluden a todos los campos del saber.

3. (A): En tu libro ¿Por qué los chilenos hablamos como hablamos? Mitos e historia de nuestro lenguaje (2015) adviertes la importancia de que consideremos la historia para pensar el castellano de Chile, y traes informaciones respecto a las diferentes influencias que Chile ha tenido a lo largo de períodos históricos. En estos momentos en Chile, con la llegada de migrantes desde Venezuela, Haití y otros lugares, ¿se podría decir que dentro de unas décadas podremos observar incorporaciones relevantes a punto de cambiar el idioma? También me gustaría que hablaras de la influencia y presencia de migración africana en Chile, y si podemos encontrar rasgos de esa presencia en el idioma o en algunos aspectos culturales o expresiones populares chilenas. En mis investigaciones sobre poesía y arte popular chileno, danzas y géneros musicales, encontré el libro Y llegaron con cadenas (2013), que rescata la presencia africana en el norte de Chile. ¿Consideras que hubo un apagamiento de esa presencia y que ahora se busca entenderla y quizás en el futuro 
tengamos más datos para pensar una influencia de estos sujetos en la constitución del castellano de Chile? ¿O quizás esa presencia no llegó a dejar marcas que se puedan constatar tan claramente? ¿Podrías por favor comentar el "lenguaje como instrumento cultural"?

(DR): Creo que el tema del contacto cultural y la transformación de la sociedad por la migración exige reconceptualizar la manera tradicional de entender las "lenguas" y los "dialectos". Autores como Roy Harris o Sinfree Makoni y Alastair Pennycook proponen que tales constructos son más bien "invenciones" movilizadas políticamente, y que lo que realmente existe en una sociedad en un momento determinado es un conjunto heterogéno de prácticas comunicativas, cuyos patrones emergentes pero siempre mutables nos dan la idea de un "sistema", que solemos llamar "lengua" y a veces con apellidos (castellana, chilena, etc.). Pensadas así las cosas, por supuesto que la ecología sociolingüística del territorio chileno se transforma y se ha transformado con la llegada de migrantes, tanto quienes hablan castellano como quienes no. La porosidad inherente de las prácticas comunicativas se manifiesta en influencias multidireccionales (préstamos léxicos: palabras de origen venezolano usadas por jóvenes chilenos, por ejemplo) pero asimismo en la heterogeneidad misma de la comunicación: multidialectalismo, multisemioticidad, etc. En fin, incluso si queremos pensar en "el" castellano de Chile, es de primera necesidad reconocer que hay influencias de múltiples actores sociales que han pasado o permanecido en territorio nacional, y que eso no es algo nuevo (la ilusión a veces alarmista de la novedad) ni tampoco es algo que vaya necesariamente a transformar radicalmente el lenguaje.

4. (A): ¿Cómo es dedicarse al castellano de Chile en Chile? ¿Hubo un momento o algo que impulsó esa motivación?

(DR): Al menos en mi caso no se trata de una motivación chovinista, sino meramente de una circunstancia: en la universidad donde me formé hay una fuerte línea de investigación sobre el castellano chileno, que se remonta al menos a la figura de Rodolfo Lenz (fines del siglo XIX), y además por supuesto que es más "fácil" investigar sobre este tema estando en Chile ya que ahí disponemos de todos los recursos bibliográficos necesarios para estudiar la historia de la lengua así como de la posibilidad de observar cómo se habla hoy. Sin embargo, mi decisión de dedicarme específicamente a este tema (la decisión de ser un "chilenólogo" por decirlo de alguna manera) se debe a que me permite pensar críticamente en los problemas del país, de mi entorno social inmediato y ojalá me 
permita aportar a solucionarlos. Así que lo veo también como una responsabilidad social profesional.

5. (A): ¿Sería correcto decir que el idioma mapuche tiene grafía? Sé que hay diferentes alfabetos del mapudungun, y he encontrado diferentes formas de escritura para una misma palabra (de todos modos, es un idioma que tiene un alfabeto hecho por personas no mapuches, pero que ahora de cierta manera sirve para ayudar a conservar esta cultura). ¿Sería correcto decir que es necesario que el mapudungun tenga alfabeto, grafía y diccionarios que destaquen su presencia en el castellano de Chile? Pienso esa cuestión de la grafía del mapudungun, por ejemplo, en el caso de una traducción al portugués o inglés que optase por acoger la palabra mapudungun en su forma escrita. ¿Cómo elegir la mejor grafía de esa palabra?

$(D R)$ : Por supuesto que sí, el mapudungun hoy cuenta con varios sistemas ortográficos, y lo interesante es que cada uno de ellos representa distintos proyectos ideológicos y distintas racionalidades (tienen distintas indicialidades). Por lo mismo, no se trata de decidir por uno $\mathrm{u}$ otro solo a partir de criterios técnicos (cuál representa mejor la pronunciación); hay una dimensión política que no se puede elidir al optar por una u otra ortografía. Y por eso también pienso que no solo es innecesario, sino también nocivo intentar homogeneizar de forma brutal, obligando a usar un solo sistema ortográfico. La absoluta homogeneidad ortográfica es más bien un epifenómeno de la hegemonía política. Otra cosa distinta es que escribir la lengua (en el sistema ortográfico que sea) pueda ayudar a transmitirla y preservarla, con lo cual sin duda estoy de acuerdo. Pero tampoco hay que fetichizar la ortografía, como que fuera lo más importante o lo único importante para darle vida a la lengua. Debe ir de la mano con mejorar las condiciones materiales y políticas de la nación mapuche, que es la condición necesaria para cualquier intento de recomponer la vitalidad lingüística.

6. (A): En Brasil estamos más próximos geográficamente al castellano de los países con los cuales hacemos frontera, pero, por otro lado, estamos bastante expuestos al español ibérico, por la presencia del Instituto Cervantes y el uso de materiales didácticos que vienen de España. ¿Cómo hablan los chilenos? Si tuvieras que explicarlo a un extranjero que no conoce el castellano de Chile, ¿qué rasgo o característica de este castellano consideras que hay que destacar? ¿Podrías comentar uno o dos aspectos fundamentales?

(DR): Partiría advirtiendo que los chilenos hablan de distintos modos (no existe un solo "castellano chileno"), pero lo que tienen en común está marcado, en 
primer lugar, por una pronunciación influida por los orígenes meridionales de la mayor parte de los españoles que llegaron a América (Andalucía y Canarias), lo cual explica que el seseo, el yeísmo y la aspiración de /s/ final estén absolutamente generalizados, así como son comunes diversos debilitamientos consonánticos en la misma posición (aunque con distintos grados de difusión entre grupos sociales). Quizá lo más distintivo del castellano chileno sea su entonación, el juego de ritmos y melodías que hacemos al hablar, que no sé bien cómo caracterizar (hay especialistas muy competentes trabajando en eso ahora mismo) pero que hace de inmediato reconocible el acento chileno. En lo gramatical, creo que lo más llamativo y diferenciador es el sistema mixto de pronombres, en donde alternan tú y vos y con las correspondientes terminaciones verbales que se encuentran creo solo en Chile: amái, tenís, salís. En el vocabulario también hay palabras que solo usan los chilenos: fome, al tiro etc., pero asimismo hay mucho compartido con el resto de quienes hablan castellano. Lo que es indiscutible es que las formas chilenas de hablar el castellano se distancian en cuestiones importantes respecto del español de Madrid y de Castilla, tienen algo más de similitud con las hablas andaluzas y por supuesto tienen una familiaridad estrecha con las hablas de otras partes de América, sin ser idéntica ni tampoco estrechamente parecida a ninguna de ellas, ni siquiera a las variedades vecinas como la rioplatense o la peruana (en esto pudo haber influido el hecho de que el territorio hoy chileno es geográficamente una especie de isla, y también el aislamiento de los grandes centros culturales durante la época de la Colonia). Recomiendo mucho prestar atención a un libro colectivo que va a salir pronto: "Lingüística del castellano chileno", editado por mis colegas Mauricio Figueroa y Brandon Rogers, y que va a ser la referencia obligada sobre estos temas en el futuro.

7. (A): En tu libro ¿Por qué los chilenos hablamos como hablamos? Mitos e historia de nuestro lenguaje (2015) comentas sobre la falta de eficacia de las censuras y prescripciones lingüísticas en el contexto histórico de Andrés Bello (17811865). ¿Consideras que actualmente sigue siendo así? ¿Ocurren aún en nuestros tiempos intentos de prescribir? En caso de que sí, ¿crees que son eficientes o provocan un efecto contrario? ¿Aún afectan a la autoestima lingüística de los chilenos?

(DR) Sí, sigue siendo así. Todavía, lamentablemente, existe una cultura normativista, aunque cada vez más circunscrita al círculo de la Academia Chilena de la Lengua y las instituciones con las que esta se ha asociado (como El Mercurio y algunas editoriales). En realidad nadie hace caso a las recomendaciones de "buen hablar", quizá excepto algunos periodistas, correctores y otros 
profesionales de la lengua, pero de ninguna manera la gramática normativa es una pasión nacional. Yo creo que en el fondo a nadie le importa mucho la corrección idiomática en el Chile de hoy, porque no es mentalmente sano estarse preocupando obsesivamente de si hablo de acuerdo o no con ciertas normas. Y es curioso, porque entonces, ¿para qué la Academia hace el esfuerzo de seguir haciendo trabajos de tipo normativo? Yo creo que es algo más bien simbólico, una especie de ritual para mostrar que son importantes ciertos valores que no son lingüísticos: la pulcritud, la homogeneidad (que es hegemonía, desde otro punto de vista), el respeto por la tradición y la autoridad, o lo que sea. El normativismo lingüístico no es efectivo en cuanto a modificar las formas de hablar, y creo que de hecho no tiene para qué ser efectivo en ese sentido si realmente su función es ritual y simbólica.

8. (A): Me parece interesante pensar que si en Chile se ha construido la idea de que los chilenos hablan mal, o deberían hablar de modo distinto, por otro lado, en las artes o en sus premiadas producciones cinematográficas se puede acceder a un castellano chileno bastante relacionado con la oralidad y con marcas de un modo de hablar que escapa de normas muy rígidas. O sea, el público internacional puede acceder y escuchar ese castellano bastante impregnado de todos los procesos que has comentado en ¿Por qué los chilenos hablamos como hablamos? Mi última pregunta es: ¿El arte y la literatura en Chile ayudan a perpetuar un castellano chileno, con su personalidad y particularidades?

$(D R)$ : Tiene que ver con lo que dije antes: en realidad nadie hace caso de las normas oficiales y entiende que están más bien de adorno, y por eso aunque alguien te diga "Uy pero qué mal hablamos los chilenos" en realidad va a seguir hablando en castellano chileno, y de buena gana, sin ninguna culpa. Y luego la literatura y el arte que tienen algún interés por mostrar una realidad social, por supuesto que no pueden falsear la realidad y mostrar a los chilenos hablando en castellano normativo peninsular; sería ridículo y hasta ofensivo. Entonces, sí, el arte y la literatura ayudan, no sé si a perpetuar (este efecto excede por mucho a las posibilidades del arte), pero sí a visibilizar y a legitimar formas de hablar que en algún momento estaban invisibilizadas. Hay ejemplos muy buenos en el cine de Raúl Ruiz, por ejemplo, o en la escritura de Pedro Lemebel. También Nicanor Parra muestra claramente la oralidad chilena, hasta cierto punto.

\section{REFERENCIAS}


¿Cómo hablan los chilenos? Conocer para traducir

Entrevista al profesor Darío Rojas

DÍAZ ARAYA, Alberto; GALDAMES ROSAS, Luis; RUZ ZAGAL, Rodrigo (eds.). Y llegaron con cadenas: las poblaciones afrodescendientes en la historia de Arica y Tarapacá (siglos XVII-XIX). Arica: Universidad de Tarapacá, 2013.

ROJAS, Darío. ¿Por qué los chilenos hablamos como hablamos? Mitos e historia de nuestro lenguaje. Santiago: Uqbar Editores, 2015.

Data de envio: 28/09/2020

Data de aprovação: $10 / 11 / 2020$

Data de publicação: 21/12/2020 